\title{
Correction to: Conjugate Time in the Sub-Riemannian Problem on the Cartan Group
}

\author{
Yu. L. Sachkov ${ }^{1,2}$
}

Accepted: 29 July 2021/ Published online: 19 August 2021

(C) Springer Science+Business Media, LLC, part of Springer Nature 2021

\section{Correction to: Journal of Dynamical and Control Systems (2021) https://doi.org/10.1007/s10883-021-09542-5}

The original version of this article was revised: Funding section has been corrected to "The work is supported by the Mathematical Center in Akademgorodok under Agreement No. 07515-2019-1613 with the Ministry of Science and Higher Education of the Russian Federation." Affiliations have been revised as follows:

${ }^{1}$ Sobolev Institute of Mathematics, Academic Koptyug avenue 4, 630090, Novosibirsk, Russia ${ }^{2}$ Ailamazyan Program Systems Institute of RAS, Pereslavl-Zalessky, Russia

Original article has been corrected.

Publisher's Note Springer Nature remains neutral with regard to jurisdictional claims in published maps and institutional affiliations.

The online version of the original article can be found at https://doi.org/10.1007/s10883-021-09542-5

Yu. L. Sachkov

yusachkov@gmail.com

1 Sobolev Institute of Mathematics, Academic Koptyug avenue 4, 630090 Novosibirsk, Russia

2 Ailamazyan Program Systems Institute of RAS, Pereslavl-Zalessky, Russia 